\title{
Analysis of Active Islanding Methods for Single phase Inverters
}

\author{
C. L. Trujillo ${ }^{1,2}$, D. Velasco ${ }^{1}$, G. Garcerá ${ }^{1}$, E. Figueres ${ }^{1}$, O. Carranza $^{3}$ \\ ${ }^{1}$ Department of Electronic Engineering, Universidad Politécnica de Valencia \\ Camino de Vera S/N, 7F, Valencia, 46022, Spain \\ Phone number: +0034 963876001, e-mail: davede@posgrado.upv.es, efiguere@eln.upv.es, ggarcera@eln.upv.es \\ ${ }^{2}$ Department of Electronic Engineering, Universidad Distrital Francisco José de Caldas \\ Carrera $7 \mathrm{~N}^{\circ}$ 40-53 Piso 5, Bogotá, Colombia \\ Phone number: +005713239300/2506,e-mail: cltrujillo@udistrital.edu.co \\ ${ }^{1}$ Escuela Superior de Cómputo, Instituto Politécnica Nacional \\ Av. Juan de Dios Bátiz S/N, 07738, D. F. (Mexico) \\ Phone number: +52 5557296000 ext 52022, e-mail: ocarranzac@ipn.mx
}

\begin{abstract}
This paper presents the analysis and comparison of the main active techniques for islanding detection used in grid-connected single phase inverters. These techniques can be divided into two classes: techniques introducing positive feedback in the control of the inverter and techniques based on harmonic injection by the inverter. The algorithms mentioned in this work are simulated in PSIM $^{\mathrm{TM}}$ in order to make a comparative analysis and to establish their advantages and disadvantages according to IEEE standards.
\end{abstract}

\section{Keywords}

Single phase inverter, Active Islanding Detection Methods.

\section{Introduction}

The condition of "Islanding" in Distributed Generators (DGs) is an electrical phenomenon that occurs when the energy supplied by the power grid is interrupted due to various factors and the DGs continue energizing some or the entire load. Thus, the power grid stops controlling this isolated part of the distribution system, which contains both loads and generation. Therefore, islanding operation of grid connected inverters may compromise security, restoration of service and the reliability of the equipment ([1], [2]).

In the case of several Distributed Generation Systems connected to a low-voltage power grid, it is possible that the amount of energy generated by the distributed system agrees with the amount of energy consumed by the loads on the grid. Under this situation, there is no energy flow towards the grid and the distributed systems may fail to detect a possible power grid disconnection, so that the DGs may continue feeding the loads leading to an "Islanding" condition. In addition, when the islanding condition happens, there is a primary security condition which forces the generator system to disconnect from the de-energized grid without taking into account the connected loads.
The "islanding" effect in inverters may result from a failure detected by the grid and the consequent switch opening, accidental opening of the electrical supply because of equipment failure, sudden changes in the electric distribution systems and loads, intentional disconnection for maintenance services either on the network or in the service, human error, vandalism or acts of nature.

There are many reasons why islanding should be anticipated in the distributed generation systems connected to the grid. The main reasons are safety, liability and maintenance of the quality of the supplied energy.

For the above reasons, islanding detection is an indispensable feature that should be taken into account in Distributed Generation Systems and different algorithms have been implemented to solve it. Islanding detection techniques can be divided into remote and local ones, and also into passive and active techniques ([3]).

Active techniques resident in the inverter, which are discussed in this article, introduce disturbances in the output of the inverter in order to affect a parameter that comes out of range in an islanding situation.

This paper is organized as follows: first, a description of the sample DG system connected to the grid; Second, different active resident methods will be presented; Next, these methods will be simulated with RLC loads according to the standards. Finally, some conclusions are presented.

\section{Sample Single Phase Inverter}

The Figure 1 shows the block diagram of the control structure of the sample inverter designed for the study of the islanding methods. The chosen DG is a $6 \mathrm{kVA}$ gridconnected photovoltaic single-phase inverter, switching at $20 \mathrm{kHz}$ with bipolar sinusoidal PWM [4].

The DC-link voltage reference is provided by a maximum power point tracking (MPPT) algorithm developed by a Perturbation and Observation (P\&O) 
method [5]. The DC-link voltage control is performed by a PI controller. A feedforward term, $I_{r e f}$, of the active power that can be delivered by the Distributed Generator, calculated from (1), is added to the output of the PI DClink voltage controller, $I_{F}$, resulting in the peak value of the reference for the current loop, $I_{r e f}$.

$$
I_{\text {ref }}{ }^{*}={ }^{n} \sqrt{n}
$$

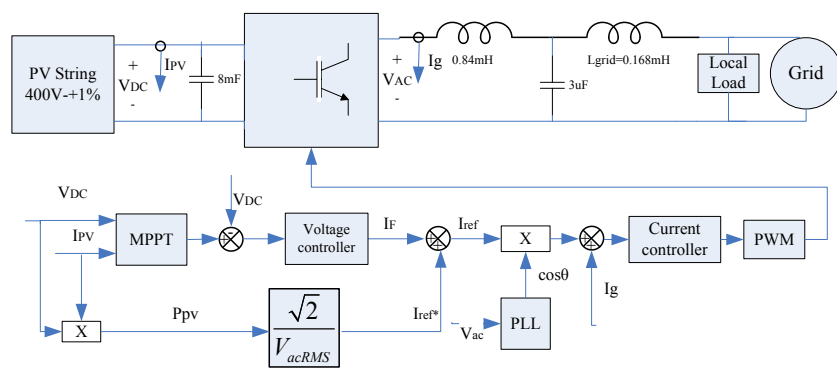

Fig.1. Block diagram of the developed inverter

The current loop reference is synchronized with the fundamental component of the grid voltage at the PCC by means of a phase locked loop in the synchronous reference frame (dqPLL) [6] [7].

The current controller was implemented by means of a harmonics compensator [8] in order to comply with the standard IEEE 929-2000 [9] in terms of both the current $\mathrm{THD}\left(\mathrm{THD}_{\mathrm{i}}\right)$ and the individual limits of harmonics.

The inverter is fed by a set of 28 photovoltaic (PV) panels of $220 \mathrm{~W}$ each one, arranged in two parallel connections of 14 series panels. The PV arrangement provides a DC-link voltage of around $400 \mathrm{~V}$ at the maximum power point (MPP), high enough for injecting to the grid $\left(230 \mathrm{~V}_{\mathrm{RMS}}, 50 \mathrm{~Hz}\right)$ without the need of a stepup transformer.

For performing the simulations, the PV array has been modelled as a current source dependent of the incoming irradiance, inserting the I-V curves of the panels as a function of the irradiance by means of a table. These techniques are based on the measurement of some parameters (voltage, current and frequency, among others) on the Distributed Generator side. They are classified as passive, based only on the monitoring of the previously described parameters, and active techniques, which intentionally introduce disturbances at the output of the inverter and observe whether the parameters outlined above are affected.

\section{Active Islanding Detection Methods}

These techniques intentionally introduce disturbances in the output on the inverter in order to determine whether they affect voltage, frequency and impedance parameter, in which case it is assumed that the grid is disconnected and the inverter is isolated from the load.

Active techniques have the advantage of remarkably reducing or even eliminating the Non-detection Zone (NDZ,) but in order to achieve their purpose they may deteriorate the quality of the voltage of the grid or even they may cause instability.
Active methods can be classified into: positive feedback based methods and harmonic injection based methods. Next, these methods will be discussed.

\section{A. Active Methods Based on Positive Feedback}

Active methods based on positive feedback present the particularity to affect, in a controlled way, voltage, frequency and the remaining parameters associated with the inverter individually or in combination, when there is a change that produces that these variables are outside assigned threshold, then through positive feedback of the variable, if the grid is not connected, it reaches levels of over/under voltage or over/under frequency ([10]), which detects the islanding situation.

There are different active methods based on positive feedback in published literature ([3], [11], [12]). Some of these methods are: variation of active power and reactive power ([11]), Sandia Voltage Shift (SVS) and Sandia Frequency Shift ([13], [14]), Slip-mode Frequency Shift (SMS) [15], Active Frequency Drift (AFD) ([16]), General Electric Frequency Schemes (GEFS) ([17]), among others.

1) Variation of active power and reactive power: This method involves injection of active power and reactive power by the inverter to the system. In islanding condition the power flow given from the inverter to the load, affects current and voltage in the PCC. The voltage variation in front of the active power injected by the inverter to the load during islanding condition is defined as:

$$
P_{D G}={ }_{L O A D}=\frac{V^{2}}{R}
$$

Differentiating $P_{D G}$ with regard to voltage and expressing it in terms of power it results:

$$
\frac{\partial}{\partial} \frac{D G}{r}=2 \cdot \frac{V}{R}=2 \cdot \sqrt{\frac{P_{D G}}{R}}
$$

Hence voltage variation in terms of power can be expressed as:

$$
\Delta=\frac{\Delta, G}{2} \cdot \sqrt{\frac{R}{P_{D G}}}
$$

Since both $R$ and $P_{D G}$ are constant, voltage variation is directly proportional to the variation of active power. Hence, it is possible to vary the active power injected by the inverter in order to bring the amplitude of the voltage outside the normal operating range and be able to detect islanding.

It is necessary to choose carefully when the power is injected because continuous variations of the injected power can perturb the Maximum Power Point Tracking (MPPT) algorithms. For these reasons, this method involves the injection of active power only when the voltage measured at the PCC exceeds a certain threshold value $(V s)$.

The time needed by the algorithm to detect a fault can be adjusted with a $K v$ that increases o decreases $d P$ proportionally to the voltage variation. This value should be chosen large enough to detect the islanding situation avoiding overcurrents which may damage the system elements. An initial value of the constant can be obtained 
from Equation 4. The current reference for the inverter control can be calculated as follows:

$$
I_{r e f}=\frac{t P+{ }_{D G}}{V}
$$

Where $d P=K v(V-V n), V n$ being the amplitude of the nominal voltage and $V$ the measurement of the feedback voltage amplitude.

Similarly to the relationship between voltage and active power, a strong dependence between frequency and reactive power exists, which may be used to develop another method of islanding, based on measuring the grid frequency. Since Std. 929-2000 recommends DG operation near to a unity power factor, the generated reactive power must be zero in normal operation. At the beginning of islanding, Equation 6 remains valid, so that the frequency depends on the values of the inductive and capacitive components of the load. Therefore, the variation of $Q$ with $\omega$ follows Equation 7, where $\omega_{o}$ is the resonance frequency of the equivalent RLC circuit, Equation 8.

$$
\begin{aligned}
Q_{D G}=Q_{L O A D} & =0=V^{2}\left(\begin{array}{c}
1 \\
\omega
\end{array}-\omega:\right) \\
\omega & =\frac{1}{\sqrt{L C}} \\
Q-0 & =\frac{t Q \mid}{d} \omega_{v=},
\end{aligned}
$$

Solving Equation 8, in order to determine the variation of the frequency as a function of $Q$ and setting the frequency of the load at the resonance frequency, it is obtained:

$$
\Delta \omega=-{ }^{2} \cdot\left\lfloor\frac{\omega L}{\lfloor L C+1}\right\rfloor Q
$$

As observed in the Equation 9, the frequency variation is directly proportional to the changes of reactive power and it can be obtained the expression of $\Delta f$ as a function of the quality factor $Q_{f}$, the resonance frequency $f_{o}$ and the active power $P_{D G}$, following the Equation 10 .

$$
\Delta=-\frac{f_{o}}{2 P_{D G}} \cdot \frac{}{2_{f}} Q
$$

The reference frequency for the inverter control can be calculated as follows:

$$
f_{r e f}=f_{g}+\zeta_{f} \cdot\left(\boldsymbol{f}-f_{g},\right.
$$

Where $f_{g}$ is the grid frequency, $\mathrm{f}$ is the measured frequency and $K_{f}$ is a constant that allows to accelerate the islanding detection. $K_{f}$ may be calculated taking into account the parameters of Equation 10.

Figure 2 shows the diagram of the method

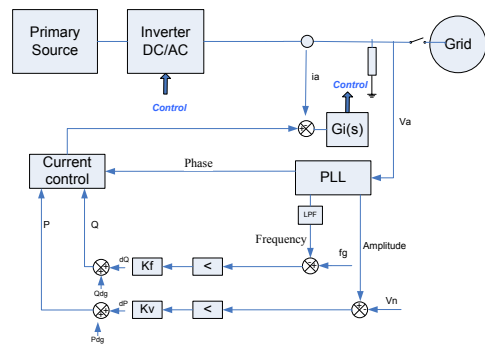

Fig. 2. Block diagram on $P$ and $Q$ injection method.

The disadvantage of this method is that it can generate false detections of islanding when several inverters are connected to the same point of the grid. Moreover, instability problems may appear because the inverter is continuously injecting disturbances into the grid.
2) General Electric Frequency Schemes (GEFS): This method injects a current disturbance into the system and evaluates the effects on the PCC. The disturbance is added to the control signals in a Synchronous Reference Frame (SRF), usually known as DQ frame. The active power is proportional to the $\mathrm{D}$ axis component and the reactive power is proportional to the $\mathrm{Q}$ axis component.

Due to it has a single-phase inverter, implementation in a DQ reference framework is not as obvious as it is in a three-phase system. However, single-phase quantities can be converted in DQ with the creation of a virtual $\mathrm{Q}$ axis as shown in Figure 3.

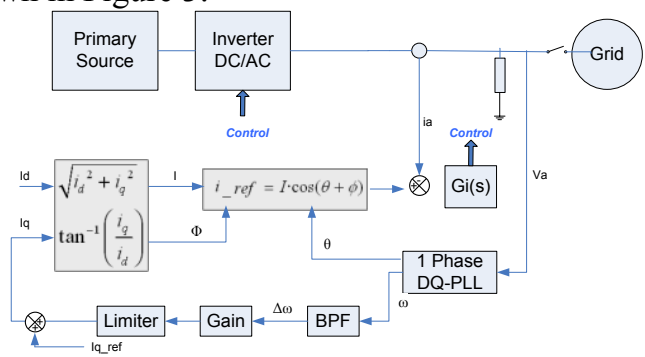

Fig. 3. Block diagram of the GEFS method.

In the frequency diagram of General Electric, to detect islanding in order to obtain the variation of the $i_{q}$ component it is used a bandpass filter. This is done because it requires minimizing the noise signal at low frequencies and the DC offset at high frequencies, caused by positive feedback. Hence, it involves selecting a bandwidth that should satisfy the reasons given above and according to standards and recommendations; it is suggested a time for islanding protection of approximately 2 seconds which is selected for designing the filter a bandwidth between $1 \mathrm{~Hz}-10 \mathrm{~Hz}$. The gain of the filter should be selected bearing in mind that when the system is connected to the grid the disturbance does not affects significantly the phase and gain margins and when islanding conditions happens, disturbance is big enough to make system unstable. The final element to consider is the limiter, which allows specifying the maximum injected current based on two premises: The first one associated with the maximum capacity of overcurrent of the inverter and the second one associated with the maximum factor of power allowed. In this method, it is affected both magnitude and the phase of the reference current, as described in the following equations:

$$
\begin{gathered}
I=\sqrt{i_{d}^{2}+i_{q}^{2}} \text { and } \phi=\tan ^{-1}\left(\frac{i_{q}}{i_{d}}\right) \\
I_{r e f}=I \cdot \cos \theta+s
\end{gathered}
$$

This method has the advantage of being easy to implement in a microcontroller, has a reduced NDZ, has minimal impact on power quality and it is very robust against disturbances in the grid. Nevertheless, injection of the disturbance signals (frequency and voltage) requires special conditions that should be as small as possible.

\section{B. Active Methods Based on Harmonic Injection.}

Active methods based on harmonic injection have the particularity of monitoring changes in grid impedance due to the injection of a particular harmonic or a sub- 
harmonic [18], [19], [20]. They are based on the idea that when grid is connected, impedance of the grid is less than the load of the harmonic frequency and the harmonic current flows into the grid, but when it is disconnected, harmonic current flows through the load that produces a harmonic voltage which can be detected. The method based on PLL implemented by [21] is explained below.

This method is based on the detection of changes in the grid impedance. The idea is to inject a harmonic current, in this case a second-order harmonic current, to change the angle of the current inverter. This is achieved by injecting a sinusoidal signal synchronized cycle by cycle which forces to smoothly modify the angle of the current inverter. A feedback signal is extracted from voltage in the PCC ( $V_{q}$ component) as a result of the injected harmonic signal.

Figure 4 shows a block diagram of anti-islanding based on changes of impedance in the grid.

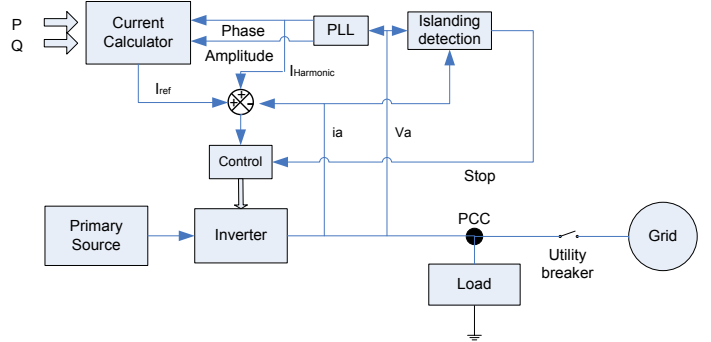

Fig. 4. Block diagram of harmonic injection method.

The operating principle of the method is described below. The injected signal $S_{\text {inj }}$ is defined as:

$$
S_{i n j}=: \cdot \sin \& \cdot \theta_{2^{\prime}} L L
$$

Where $k$ is the gain used to choose the amount of disturbance necessary for the islanding detection and $\theta_{P L L}$ is the angle made by the PLL. As it can be observed in Equation 14, a second harmonic has been entered which will be added to the PLL phase and then scaled by magnitude of the reference current of the system.

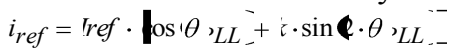

The value of $k$ should be chosen taking into account three premises: the first one is that it has to be big enough so it can detect islanding condition. The second premise is that its value is not as big as it would produce an increase of THD in the superior current in limits set by standards and the third premise is that it should not affect in a significantly way the amplitude of the reference current. In Equation 15 it can be observed that the perturbation can be treated in terms of a percentage of the reference current. In this case was used a perturbation with an amplitude of $1 \%$, which meets the given above conditions.

When the inverter is connected to the grid, the action of adding the disturbance described above is reflected in the feedback signal of voltage in the PCC. The feedback signal has twice the fundamental frequency and its amplitude is related to the value of the grid impedance. This feedback signal can be extracted from the Park Transformation in terms of $V_{q}$. After the transformation, the frequency of the feedback signal becomes half of it, as shown below:

$$
v_{q}=-\sin \theta \cdot v_{\alpha}+\cos \theta \cdot v_{\beta}
$$

Considering a system of orthogonal voltages of the feedback voltage $\left(V_{\alpha}\right.$ y $\left.V_{\beta}\right)$ due to the injected signal and considering $\alpha$ and $\beta$ voltages, they can be represented as:

$$
\begin{aligned}
& v_{\alpha}=\cos \ell \cdot \theta \text {; and } \\
& v_{\beta}=\cos \left(2 \cdot \theta-\frac{\tau}{2}\right)=\sin \ell \cdot \theta
\end{aligned}
$$

Replacing the values of Equation 17 in Equation 18 and solving, it is obtained:

$$
\begin{gathered}
v_{q}=-\sin \theta_{-}^{\circ} \cdot \cos \boldsymbol{C} \cdot \theta_{-}^{-}+\cos \theta_{-}^{\circ} \sin \boldsymbol{Q} \cdot \theta_{-} \\
v_{q}=\operatorname{in} \theta^{-}
\end{gathered}
$$

The signal of feedback voltage can be extracted after Park Transformation through a resonant filter tuned to fundamental frequency. After this, the peaks in absolute value are detected from signal $V_{q}$ and it is calculated the average in $50 \mathrm{~Hz}$ and $5 \mathrm{~Hz}$. Finally, the difference between the two averages is taken to determine whether it is inside or outside certain threshold value. If it is outside the threshold value, it is activated a delay to establish if the conditions persists, and in case it happens, islanding condition is activated.

The main advantages of this method is that it does not affect the zero crossings of the current, disturbance amplitude is as little as it can be injected all times without affecting the THD of the current significantly and it presents a very low NDZ. The method drawbacks are: it slightly degrades the quality of the power by having a constant disturbance and it can have trouble detecting islanding in certain grid disturbances which might match with injected harmonics.

\section{Simulations results}

This section presents the main results of simulations of different methods described above. These simulations were development in PSIM ${ }^{\mathrm{TM}}$ [22] and tested on the inverter presented in section 2, following the requirements of IEEE Std. 929-2000 (type of load and quality factor); in all cases was used an RLC load with a quality factor of 2.5 .

Figure 5. a. shows the results of the islanding detection method based on variation of active power through the use of feedback voltage. In this graph it is possible to observe how the single phase inverter disconnection is produced within times set by standards [9]. Likewise, in Figure 5. b. are obtained similar results to those in islanding detection method based on variation of reactive power through the use of frequency feedback. The value of the constants $K_{v}$ and $K_{f}$ determine the trip time.

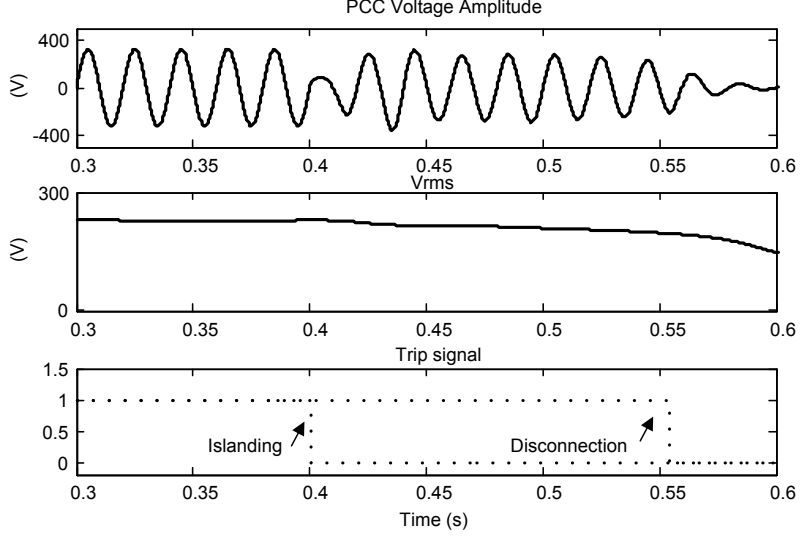

(a) 

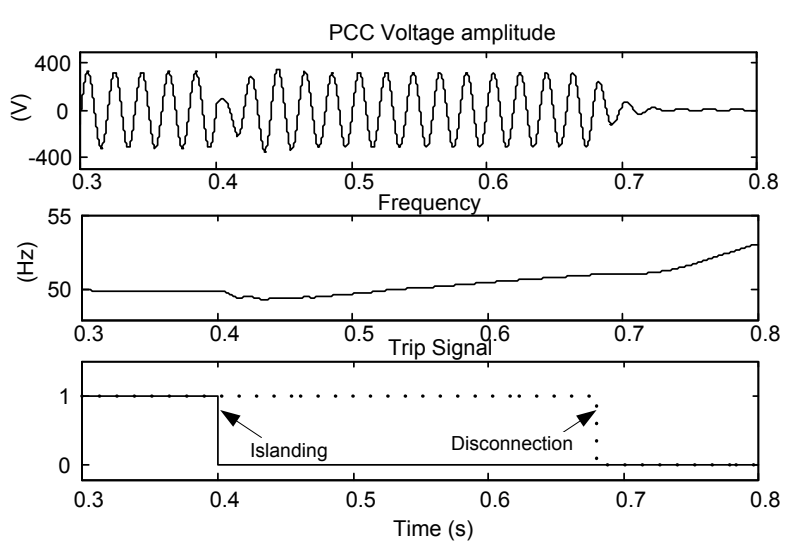

(b)

Fig. 5. (a) Active power injection. PCC voltage, RMS Voltage and islanding detection. (b) Reactive power injection. PCC voltage, frequency and islanding detection.

Figure 6 shows the results of the FSGS method. It can be seen that when islanding is generated there is a variation in component $I_{q}$, that makes the reference current to vary in magnitude and angle so a feedback effect happens. It takes the frequency (or voltage) of the single phase inverter outside established limits.
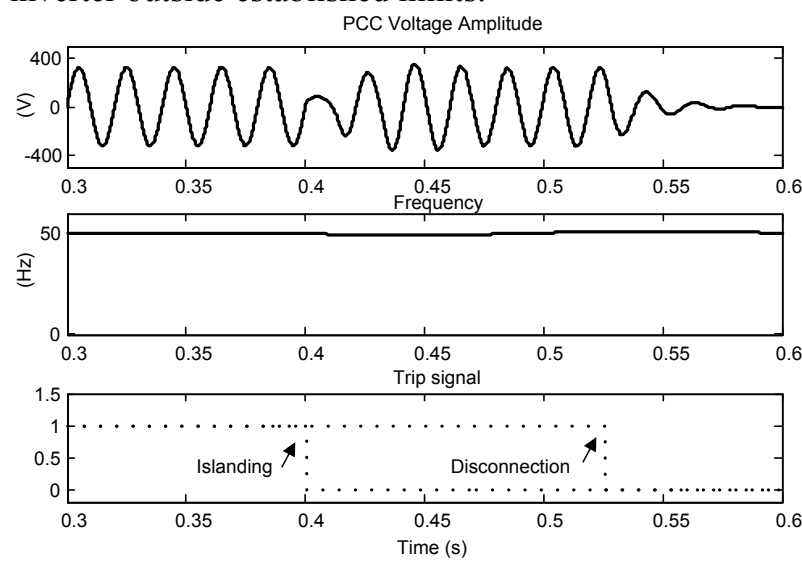

Fig. 6. GEFS. PCC voltage, frequency and islanding detection.

Figure 7 shows when islanding situation occurs, the component $V_{q}$ changes as a result of the variation in impedance at the frequency of the harmonic injected, which allows to detect the islanding condition.

PCC Voltage amplitude
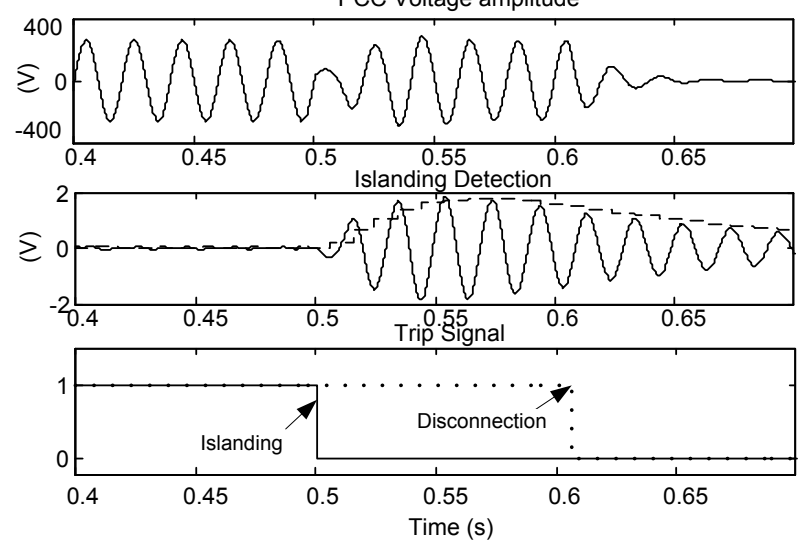

Fig. 7. Impedance detection. PCC voltage and islanding detection.

For all the methods previously simulated, the THD in current never exceeded $3.2 \%$. The most critical case happened in the methods of variation of active and reactive power whereas for the other methods the $\mathrm{THD}_{\mathrm{i}}$ did not increase significantly because disturbance was only applied only in certain conditions and its magnitude became as small as the methods allowed. Table I provides information to compare the trip time of the different methods.

TABLE I

COMPARISON OF THE DIFFERENT ACTIVE METHODS FOR ISLANDING DETECTION

\begin{tabular}{|c|c|}
\hline Method & Trip time \\
\hline $\begin{array}{c}\text { Active power } \\
\text { variation }\end{array}$ & $0.16 \mathrm{~s}$ with $K v=20$ \\
\hline $\begin{array}{c}\text { Reactive power } \\
\text { variation }\end{array}$ & $0.28 \mathrm{~s}$ with $K_{f}=4$ \\
\hline GEFS & $\begin{array}{c}0.1 \text { to } 0.2 \mathrm{~s} \text { as a function of the } \\
\text { size of the disturbance }\end{array}$ \\
\hline $\begin{array}{c}\text { Impedance } \\
\text { detection }\end{array}$ & $\begin{array}{c}0.1 \text { to } 0.2 \mathrm{~s} \text { as a function of the } \\
\text { size of the disturbance }\end{array}$ \\
\hline
\end{tabular}

\section{Conclusion}

In this paper was presented an analysis of various active methods resident in the inverter for islanding detection in single phase inverters. It became evident that for the same test conditions as established by the IEEE 929 all methods met, however the positive feedback based methods have a longer trip time that those based on harmonic injection because positive feedback methods should reach the threshold of UOV or UOF, whereas methods based on harmonic injection what is sought is to detect variations in the impedance of the grid, which allows to work with smaller detection thresholds. On the other hand, despite these methods are based on disturbing the system and degrading the power quality, their effect is not significant and they are within the harmonic distortion limits set by standards.

\section{References.}

[1] M, Pietzsch, "Convertidores CC/CA para la conexión directa a red de sistemas fotovoltaicos: comparación entre topologías de 2 y 3 niveles," Bachelor thesis, Universidad Politécnica de Cataluña, España, Dec. 2004.

[2] V. Task, "Evaluation of islanding detection methods for photovoltaic utility-interactive power systems," Tech. Rep. IEAPVPS T5-09:2002, March. 2002.

[3] P. Mahat, C. Zhe and B. Bak-Jensen, "Review of islanding detection methods for distributed generation," in Third International Conference on Electric Utility Deregulation and Restructuring and Power Technologies, 2008, pp.2743-2748.

[4] Mohan, N., Underland, T.M.\& Robbins, W.P. 2003 Power electronics: converters, applications, and design. 3th ed. International. John Wiley \& Sons.

[5] T. Esram and P.L. Chapman, "Comparison of Photovoltaic Array Maximum Power Point Tracking Techniques," Energy Conversion, IEEE Transactions on , vol.22, no.2, pp.439-449, June 2007.

[6] M. Ciobotaru, R. Teodorescu and F. Blaabjerg, "A new singlephase PLL structure based on second order generalized integrator", in Record of IEEE PESC 2006, Jeju, Korea, p. 1511-1516.

[7] M. Liserre, A. Timbus, R. Teodorescu, F. Blaabjerg, "Synchronization methods for three phase distributed power generation systems. An overview and evaluation," PESC 2005, Recife, Brasile.

[8] M. P. Kazmierkowski, R. Krishnan, F. Blaabjerg, "Control in power electronics," Academic Press, London, 2002. 
[9] IEEE recommended practice for grid interface of photovoltaic (PV) systems, IEEE Std. 929, 2000.

[10] M. Francesco De, L. Marco, D. A. Antonio, and P. Alberto, "Overview of Anti-Islanding Algorithms for PV Systems. Part I: Passive Methods.” Proc. of EPE-PEMC, 2006, pp. 1878-1883.

[11] M. Francesco De, L. Marco, and D. A. Antonio, "Overview of AntiIslanding Algorithms for PV Systems. Part II: Active Methods.” Proc. of EPE-PEMC, 2006, pp. 1884-1889.

[12] I.J. Balaguer, K. Heung-Geun, F.Z. Peng and E.I. Ortiz, "Survey of photovoltaic power systems islanding detection methods." Industrial Electronics, 2008. IECON 2008. 34th Annual Conference of IEEE, pp.2247-2252, m10-13 Nov. 2008

[13] J. Stevens, R. Bonn, J. Ginn, S. Gonzalez, and G. Kern, "Development and testing of an approach to anti-islanding in utility interconnected photovoltaic systems," Sandia Report SAND 20001939, Aug., 2000. Available: http://photovoltaics.sandia.gov/docs/PDF/0800steve.pdf.

[14] P. Sanchis, L. Marroyo and J. Coloma, "Design methodology for the frequency shift method of islanding prevention and analysis of its detection capability." Progress in Photovoltaics: Research and Applications, Vol. 13, No. 5, pp. 409-428, 2005. Available: http://dx.doi.org/10.1002/pip.613

[15] L.A.C. Lopes and H. Sun, "Performance assessment of active frequency drifting islanding detection methods." IEEE Trans. On Energy Conversion, Vol. 21, No. 1, March 2006, p. 171-180.

[16] M. E. Ropp, M. Begovic and A. Rohatgi, "Analysis and performance assessment of the active frequency drift method of islanding prevention," IEEE Transactions on Energy Conversion, Vol. 14, No. 3, pp. 810-816, September 1999.

[17] Z. Ye, R. Walling, L. Garces, R. Zhou, L. Li and T. Wang, "Study and Development of Anti-Islanding Control for Grid-Connected Inverters." General Electric Global Research Center, Niskayuna, New York, USA, 2004. Available: http://www.nrel.gov/docs/fy04osti/36243.pdf

[18] C. Zhang, W. Liu, G. San and W. Wu, "A Novel Active Islanding Detection Method of Grid-connected Photovoltaic Inverters Based on Current-Disturbing." Power Electronics and Motion Control Conference, 2006. IPEMC 2006. CES/IEEE 5th International, Vol.3, pp.1-4, Aug. 2006

[19] M.E. Ropp, M. Begovic and A. Rohatgi, "Prevention of islanding in grid-connected photovoltaic systems", Progress in Photovoltaics: Research and Applications, Vol. 7, No. 1, pp. 39-59, 1999. Available: http://www3.interscience.wiley.com/cgibin/fulltext/40007275/PDFSTART

[20] A. V. Timbus, R. Teodorescu, F. Blaabjerg, U. Borup, “Online grid measurement and ENS detection for PV inverter running on highly inductive grid.”" IEEE power electronics letters, Vol. 2, No. 3, pp. 77-82, September 2004.

[21] M. Ciobotaru, V. Agelidis and R. Teodorescu, "Accurate and lessdisturbing active anti-islanding method based on PLL for gridconnected PV Inverters." Power Electronics Specialists Conference, 2008. PESC 2008. IEEE, pp.4569-4576, June, 2008

[22] PSIM 7.0 User's Guide (2006), Powersim Inc., March 2006. 